\title{
Practical Research on Teaching Reform of Engineering Surveying Course
}

\author{
Lin Longbin $^{1}$, Zhang Rongjie ${ }^{1}$, Shen Yaohui ${ }^{1}$ \\ ${ }^{1}$ Department of Civil Engineering, Xiamen University Tan Kah Kee College \\ Fujian, Zhangzhou, PR of China, 363105, China \\ * Corresponding author
}

Keywords: Non-surveying and mapping major; Engineering Surveying; teaching reform; Micro-lectures.

Abstract. The teaching reform of the current course Engineering Surveying lacks the application of Internet and information technology and there are still some problems in its teaching. This paper takes the teaching reform of Engineering Surveying for non-surveying major students as an example to explore the teaching method by using APP software, Micro-lectures, Flipped Class Model and other teaching means, which can well solve problems in teaching and achieve good teaching results. Teaching achievements of this paper can provide reference for colleagues.

\section{Introduction}

Engineering surveying course is an important branch of surveying and mapping science and it is an applied course which mainly studies theories, methods and technologies of surveying and mapping of geometric entities and abstract geometric entities [1]. This course mainly aims at students of surveying and mapping major and students of non-surveying majors. It has different teaching requirements for teaching objects of different majors and they are slightly different in terms of teaching methods, teaching contents, teaching means and practical skills that students are required to master. This course will mainly cultivate advanced surveying and mapping science and technology talents with relatively complete modern surveying and mapping knowledge who can master basic surveying and mapping principles and methods and who will engage in surveying and mapping post after their graduation. The goal for cultivating non-surveying major talents is not to train advanced surveying and mapping science and technology talents, but to serve demands of different major practice. Most students graduating from the university do not work in surveying and mapping posts. Non-surveying majors mainly refer to those majors related to civil engineering, such as civil engineering, engineering project management, engineering cost and water supply and drainage.

This paper summarizes teaching reform achievements of the course Engineering Surveying. It finds that under the background of the rapid development of Internet and multimedia technology, the technology has not been used in the course of teaching reform by colleagues. However, APP software, Micro-lectures and Flipped Class Model and other teaching methods on the basis of the information technology has played an important role in the teaching reform. The author applied this technology and means to the teaching reform of Engineering Surveying for non-surveying and mapping undergraduate major students, which enriched the research achievements in this field.

\section{Current Situations of Teaching Reform of Engineering Surveying}

Researches on teaching reform of Engineering Surveying course were mainly divided into three main levels: surveying and mapping majors; non-surveying and mapping undergraduate majors and high-vocational and high-specialized colleges. Course teaching reforms at different levels have different focuses.

Research achievements of Engineering Surveying course teaching reform for surveying and mapping majors are as follows: Ding Shijun and other experts from Surveying and Mapping School of Wuhan University [2] discussed the application of heuristic teaching methods. They fully mobilized students' initiative of independent learning through carrying out heuristic teaching; trained students' ability in analyzing and solving problems and improved teaching quality. Zhang Zhenglu [1] from Surveying and 
Mapping School of Wuhan University summarized the teaching status, existing problems and disciplinary features of Engineering Surveying. Their teaching thoughts showed us that our course teaching shall lay out the relationship between teachers and students and the teaching relationship; our teaching contents should make clear the priority and choices and at least 2-3 teachers shall be assigned to teach courses; we should emphasize textbook construction.

Engineering Surveying teaching reform research achievements of non-surveying major undergraduates are as follows: Hu Wusheng and other teachers from Traffic School of Southeast University [3] introduced some expression and feelings for "Engineering Surveying" discussion-based teaching reform of Southeast University. Discussion-based courses cultivated students' autonomous learning ability and the preliminary research ability, changed traditional teaching mode and the relationship between teachers and students. The classroom became a place for teachers and students to explore problems and teachers become a facilitator and collaborator for students to learn. This way helped achieve good teaching effect. Guo Fanbo [4] from Architecture and Engineering School of Taizhou University helped students improve their practical and operational skills by adopting the project-based teaching method and reforming the evaluation system. They gained professional experience in teaching course and mastered key engineering surveying skills of "precise operation and calculation". Yu Ying [5] from School of Urban Construction of Jiangxi Normal University reformed teaching contents of the courses and applied heuristic, exploratory and project-based teaching modes in the teaching. They explored practical teaching schemes of engineering surveying according to characteristics of three non-surveying majors of engineering management, urban planning and architecture.

Engineering surveying teaching reform of higher vocational colleges focuses on students' obtaining engineering experience and their improvement of their employment ability. Liu Wenlong [6] of Beijing Vocational and Technical College put forward that we shall introduce a new management mode of "school-enterprise double tutorial system" in engineering surveying professional practice so as to achieve the good connection between on-the-job practice students and the employment posts and promoted the in-depth integration of school-enterprise. Yuan Hui et al. [7] of Jiangxi University of Science and Technology applied practical teaching method in the course teaching to guarantee the implementation of practical teaching method by means of virtual simulation practical training and on-site base practical training. Meanwhile, in order to strengthen the combination of production and learning, the identification of practical training unit was introduced into the evaluation system of practical teaching quality.

The above research results show that Internet and multimedia technologies are not well applied in the teaching reform. In addition, some problems in the course teaching, such as the negative effect of mobile phones in the classroom, the compression of class time and the lag of textbooks, remain to be solved. Therefore, in order to solve the above problems, this paper tries to apply new technologies, new means and new models to the engineering surveying course teaching reform of non-surveying major.

\section{New Attempts of Course Teaching Reform}

\subsection{Application of mobile APP software.}

With the development of mobile phone technology, mobile phones have more and more powerful hardware and functions and they can even replace most functions of computers. People tend to depend on mobile phones increasingly. Therefore, mobile phones have an irreplaceable place in our life. How to introduce positive mobile phone elements into the teaching is a problem to be considered by education colleagues. Nowadays, most teachers are still confused about how to resist the negative impact of mobile phones used by students in class. However, the author thinks that if it is impossible for students to resist the temptation of mobile phones, why not guide students to use mobile phones as learning tools and make them play their powerful functions.

In his teaching course, the author uses the mobile APP "learning pass", which is a platform for knowledge dissemination and management sharing based on the principle of nervous system in China. The platform itself has many excellent information resources. Besides, it also provides one-stop learning 
environments for users and it can create course learning classes with the software as the platform. This App also uses course learning classes as management units of teaching activities and uses course chapters, learning materials, discussion, notification and background data management functions in the software to help course teaching. Before class, the author refines, summarizes and summarizes knowledge points of course chapters. Its contents are written with more charts and few words and the contents are supplemented by micro-lectures videos. All contents are shown to students through "course chapters", and students are required to preview those contents in advance. Students can make full use of Internet technology and mobile phone as the terminal to study in their fragmented time. Besides, they can establish the structure system for chapter knowledge. Teachers can use background data to manage data so as to grasp students' situation in previewing and grasping knowledge and to timely adjust key points of classroom teaching.

\subsection{Application of micro-lectures means.}

Micro-lectures refers to a teaching method in which teachers focus on a single teaching task (key points, difficult points, difficult points) or skill and other single teaching tasks in their teaching process both inside and outside the classroom. It is characterized by clear objectives, strong pertinence and short teaching time. This teaching method has become a hot spot of education informatization and an important carrier for the effective combination of information technology and teaching in all education levels.

Engineering surveying was highly practical and some knowledge points were relatively abstract. Although a large number of pictures are used to course chapters to help students preview contents, there are still some difficulties which can not be grasped by students. In practice, the author recorded important knowledge points, difficulties, instrument introduction and operations in the course into micro-lectures video and placed them in the "course chapter". In the teaching process, the this paper adopts some multimedia technologies such as texts, pictures and videos and makes them well combined with Internet technologies, which provides students with good preview experience and effectively improves their learning efficiency.

\subsection{Implementation of flipped class model.}

Flipped Class Model refers to the course teaching model that transfers the right to make decisions from teachers to students by adjusting the time inside and outside the classroom. When Flipped Class Model is used, teachers will no longer use class time to teach students information. Students can finish their learning independently outside the classroom. In the classroom, students will have more time for interactive communication and independent thinking, while teachers will give targeted explanations to students. Teachers play a role of teaching assistant and guide, which breaks the traditional central position of teachers.

The organization of Flipped Class Model consists of the following parts: preview question and feedback, teacher's intensive answering, discussion of questions in the course chapter and exploration of knowledge of this chapter in the engineering application scenario. In this chapter, students and teachers occupy $50 \%$ of the time respectively. With the transformation of this teaching mode, students can improve their learning skills and engineering practice skills and teachers can improve their engineering practice skills. Basic knowledge points of textbooks are no longer key points of classroom teaching, but the focus of students in their preview. In addition to answering questions in the class, this paper mainly discusses application scenarios of theoretical knowledge in the practice, which puts forward higher requirements for teachers' engineering practice skills. Teachers can improve their comprehensive practical skills through preparing lessons and carrying out teaching activities. Both teachers and students can benefit a lot form the Flipped Class Model teaching mode. The transfer of emphasis in classroom teaching makes up for the shortage of teaching materials.

\subsection{Practice teaching.}

With the implementation of Flipped Class Model teaching, students can further explore application scenarios of theoretical knowledge in engineering practice, which can make content design of experimental teaching better match actual applications. With the changes of practical teaching focuses, we should change teaching focus from training students' instrument operation skills to the improvement 
of their engineering practice ability. In experimental teaching process, if teachers can simulate applied scenes discussed in the classroom in the experimental courses, students will be able to deeply understand measurement requirements of engineering practice and master methods for surveying instruments' being used to meet measurement requirements, which will help train students' comprehensive ability in solving practical engineering problems.

In the practical teaching, teachers also arrange practice in the construction sites. Measurement problems involved in the construction are analyzed one by one and measurement operations are observed on site. In this teaching process, students can further verify classroom ideas, discover the difference between the measurement in engineering practice and the measurement in the simulated environment in the experimental course, and deepen their understanding of theoretical knowledge by understanding measurement schemes in practical applications. The on-site teaching form will no longer make engineering surveying teaching abstract and boring, instead, the teaching becomes concrete, vivid and interesting, which can better mobilize students' desire for knowledge.

\subsection{Major difficulties in reform practice.}

The successful implementation of Flipped Class Model requires students to do sufficient preview work before class, but the work may not be agreed by all students. The traditional spoon-feed teaching mode has made some students accustomed to passively accepting knowledge. They are unwilling to put too much energy into learning and they are inclined to adopt easy learning methods. The teaching mode of Flipped Class Model that wins the approval of teachers and students, because it provides sufficient communications between them. However, because of the inertia of students, preview links may not be effectively implemented. Though the application of Internet technology, multimedia information and APP software as well as the implementation of various measures such as teacher's pre-class Q\&A and online discussion can provide students with preview help from various dimensions in a three-dimensional way, if students do not take part in it actively, they will still fail to achieve results as expected. In a word, students' lack of active input is the biggest problem faced by this teaching reform, and how to win the cooperation of students is the focus of the next teaching reform.

\section{Summary}

This paper summarizes main achievements of the teaching reform of the Engineering survey course and finds out the shortages of the teaching reform of engineering survey course for non-survey major students. The author applies the currently popular teaching methods, such as Micro-lectures, Flipped Class Model and mobile phone APP, to the teaching reform of this course, and achieves some results.

(1)The application of APP software and Micro-lectures, students can make full use of the fragmented time in life to study, which improves their learning efficiency and solve the difficulties of insufficient class hours to some extent.

(2)Thanks to the implementation of Flipped Class Model, content designs of classroom teaching and experiment are more inclined to engineering application, which can better meet requirements of application-oriented undergraduate teaching and alleviate the problem of lagging teaching materials.

(3)Both teachers and students have gained a win-win result in the teaching reform practice. Students can improve their comprehensive practical ability in solving engineering problems while teachers can improve their teaching level and practical skills and make them better meet standards of double-qualified composite talents.

\section{References}

[1]. Zhang Zhenglu. Teaching thinking of "Engineering Surveying course [J]. Bulletin of Surveying and Mapping, 2014, (10): 125-127.

[2]. Ding Shijun, Guo Jiming, Cheng Xinming. Explanation of Several Problems in Heuristic Instruction of "Foundation of Geodesy" [J]. Bulletin of Surveying and Mapping, 2014, (3): 124-127. 
[3]. Hu Wusheng, Zhang Zhiwei, Wang Lei. Teaching Practice and Thinking of the Discussion-based “Engineering Surveying” Course [J]. Bulletin of Surveying and Mapping, 2016, (1): 138-141.

[4]. Guo Fanbom Qiu Zhanhong. Research on Project Teaching Reform of Engineering Surveying [J]. Bulletin of Surveying and Mapping, 2014, (6): 128-130.

[5]. Yu Ying, Zhao Haiyun. Teaching Reform Research of Engineering Surveying Course for Non-surveying Major Students under the Influence of Excellence Program [J]. Bulletin of Surveying and Mapping, 2015, (12): 122-124.

[6]. Liu Wenlong. University-enterprise Dual Tutorial System: New Management Mode of Post Practice of Engineering Surveying Major Students[J]. Bulletin of Surveying and Mapping, 2014, (8): 128-130.

[7]. Yuan Hui, Yan Bing. Practical Teaching Research of Building Engineering Surveying for Higher Vocational College Students [J].Vocational \& Technical Education Forum, 2014, (11): 71-73. 